\title{
Selected Issues of the Internal Combustion Engine Turbocharger Operation
}

\author{
Wincenty Lotko ${ }^{1 *}$, Marcin Lechowski² \\ 1 University of Technology and Humanities in Radom, ul. Malczewskiego 29, 26-600 Radom, Poland \\ 2 Bosch Serwis Logis in Radom, ul. 1905 roku 3/9, 26-600 Radom. Poland \\ * Corresponding author's e-mail: w.lotko@uthrad.pl
}

\begin{abstract}
A combustion engine turbocharger works in most difficult conditions due to high temperatures of the fuels it is driven by, vibrations and high rotational speeds of its shaft up to 200 thousand rpm. In addition, under these conditions, there are difficulties with lubrication of the blade axes. Thus, the combustion engine turbocharger is exposed to the damages occurring during the engine operation process. The frequency of damages was determined on the basis of tests for a selected group of vehicles. The object of detailed author's own research was the Audi 3.0 V6 TDI engine of the Audi A6 C6 car which cooperated with a Borg Warner turbocharger with a variable angle of turbine steering wheel blades. These positioners are also exposed to adverse conditions: mainly vibrations and high temperatures. They are subjected to frequent damages, which often affect the engine control parameters. An analysis of the positioner element damage as well as a group of testers to assess their technical condition was made. The evaluated testers were allowed only to determine the efficiency of the turbocharger, but without indicating its technical condition or its positioner separately. Consequently, the author's own research methodology and the construction of a new tester for the electromechanical turbocharger adjuster was developed. The necessary tests for the vehicle mileage up to $350,000 \mathrm{~km}$ were carried out. The self-designed tester can also estimate the degree of electromechanical wear of the positioner in the engine supercharging system as well as the resistance of its movements resulting from the pollution of the VTG turbocharger mechanism with the turbine steering wheel positioner, with variable geometrical parameters.
\end{abstract}

Keywords: diesel engine, turbocharger, variable angle, turbine steering, wheel blades, electromechanical turbocharger positioner, boost pressure

\section{INTRODUCTION}

The manufacturers of modern internal combustion engines for vehicles must meet a number of strict requirements like: low fuel consumption, required noise level, limited exhaust emissions as well as the vehicle lifespan at the lowest possible cost. The user's additional requirement as far as the engine is concerned, is a relatively high power level per liter of its displacement. Currently, it can be assumed that in passenger cars, for spark and compression ignition engines, the power level exceeds $75 \mathrm{~kW}$ per liter of its displacement. In both types of engines, their control systems must meet such requirements. For this purpose, the fuel injection system, e.g. in a compression-ignition engine, must supply fuel at a pressure of approx. $260 \mathrm{MPa}$ and repeatedly inject the initial fuel doses and the main dose in a precisely defined piston position in relation to its top dead centre.

In compression ignition engines, the Common Rail injection system meets these requirements. Its main advantage in comparison to other compression injection engine systems is the separation of pressure generation and fuel injection processes regardless of the engine speed and the dose of the injected fuel [9].

In order to meet the strict EURO standards regarding the emission of limited exhaust fume components, the latest, fully electronic control 
systems for a compression ignition engine, e.g. BOSCH EDC17, must calculate the actual dose of the injected fuel for each injection and its individual phases for multiphase injection with an appropriate dose of air.

Meeting the requirements of passenger cars and trucks can take place when the diesel compression ignition engines are charged with compressed air using a turbocharger. In this case, the technical condition assessment of the Audi 3.0 V6 TDI engine, equipped with a turbocharger with a variable angle of turbine blades (VTG), and an adjustable electromechanical positioner will be made.

Obtaining the required parameters by the diesel engine in the process of fuel injection and combustion requires the use of a controller for the implementation of the mentioned processes.

In the process of calculating the quantitative fuel-air mixture, it is necessary for the controller to know a number of engine operating parameters, such as engine and drawn air temperature, exhaust gas temperature, engine load and its rotational speed. The measurement of these parameters is carried out by means of appropriate sensors, which additionally support the supervision over the proper operation of the engine control system as well as its diagnostics. The measurement of regulated parameters, such as fuel pressure and the engine charge air, allows the engine controller to compare the measured values with the programmed ones. The sensors used to build the engine management system change their characteristics during the engine operation. This, in turn, affects the correctness of parameters and, as a consequence, it may lead to the increase in fuel consumption, limited exhaust gas component emissions and even engine noise $[1-5,11,12]$.

As a result of the literature analysis of selected items, no studies regarding the relationship between the diagnostic parameters of the engine and the mileage of the vehicle or its operating time have been found so far. Such research is carried out by car companies, but, for understandable reasons, they are not published.

\section{Characteristics of the test object}

A significant number of currently manufactured diesel engines are equipped with turbocharging systems, i.e with a turbocharger, including the ones with a variable angle of turbine steering wheel blades (VTG,VNT).
Electromechanical positioners are increasingly often used to regulate the charge air pressure in this group of turbochargers.

On the basis of the author's research carried out on a group of Mercedes-Benz Sprinter W906 2.1 DCI and VW Crafter 2.5 TDI vehicles, it was found that the damages of the engine charging system $-49 \%$ [8] occurred most frequently. This confirms the desirability of testing turbocharger posotioners. Understanding the wear process of the turbocharger control mechanism allows determining the percentage estimation of its motion resistance caused by the contamination of the turbine steering wheel blades (turbocharger VTG mechanism).

Figure 1 [14] shows the design of the tested Audi 3.0 V6 TDI engine of the Audi A6 C6 passenger car, and Figure 2 shows a Borg Warnner turbocharger with an electromechanical positioner for the Audi 3.0 V6 TDI engine; Table 1 contains its basic technical parameters.

\section{Operational damages to the electromechanical turbocharger positioner}

Downsizing, which is currently used by manufacturers in combustion engines is possible for technical implementation owing to the use of turbocharging. A good example of this phenomenon is a three-cylinder engine developed by Mahle company, with the capacity of 1.21 , power of $144 \mathrm{~kW}$, torque of $287 \mathrm{Nm}$ and reduced emissions by $30 \%$. With traditional design solutions, such performance would be provided by a 2,4 $1[5,6]$ engine. The development

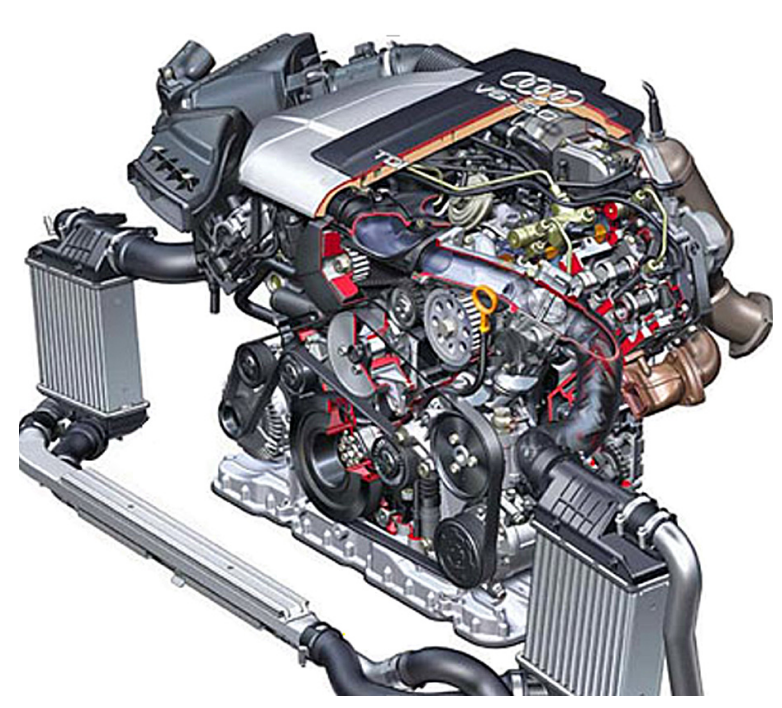

Fig. 1. Audi 3.0 V6 TDI $165 \mathrm{~kW}$ engine [14] 


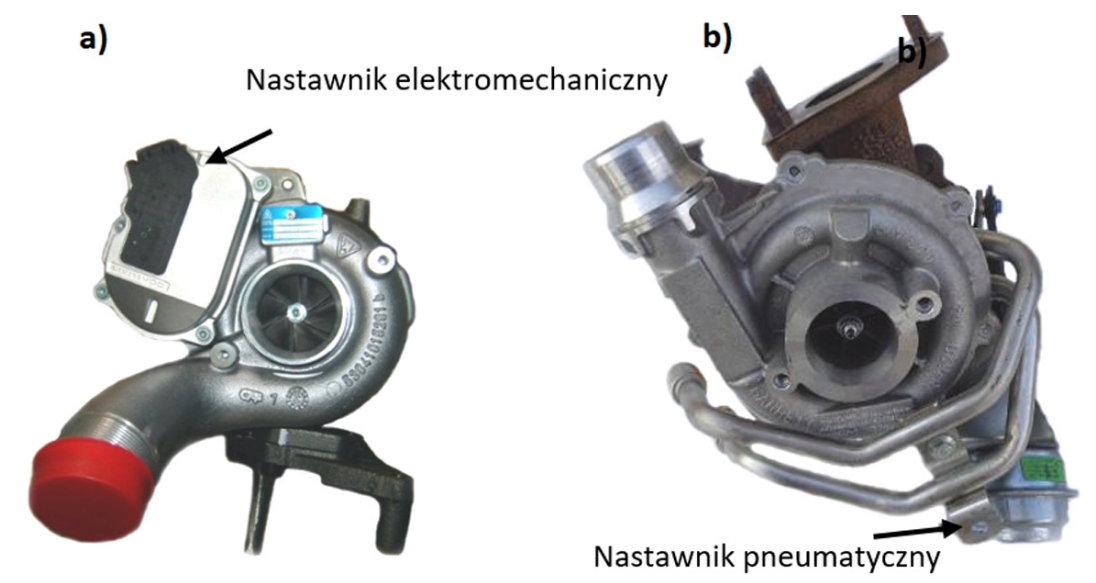

Fig.2. BorgWarner turbocharger with electromechanical adjuster (a), used in the Audi 3.0 V6 TDI engine and Garrett turbocharger with pneumatic actuator (b) used in the Renault $2.3 \mathrm{dCi}$ engine

Table 1. Basic technical data for the Audi 3.0 V6 TDI research engine [14]

\begin{tabular}{|l|l|}
\hline \multicolumn{1}{|c|}{ Engine parameters } & \multicolumn{1}{c|}{ Parameter description } \\
\hline Engine type & Turbo Diesel \\
\hline Capacity & $2967 \mathrm{~cm}^{3}$ (3.0 V6 TDI) \\
\hline Type & BMK \\
\hline Number of cylinders & 6 \\
\hline Number of valves & 24 \\
\hline Neutral gear & $760+/-100$ rpm \\
\hline Firing order & $1-4-3-6-2-5$ \\
\hline Type of a turbocharger & $\begin{array}{l}\text { Turbocharger with a variable angle } \\
\text { of turbine blades (VTG) controlled } \\
\text { by an electromechanical positioner }\end{array}$ \\
\hline Power & 165 kW -4000 rpm \\
\hline Torque & 450 Nm - 1400-3250 rpm \\
\hline Injection system & Common Rail \\
\hline Injectors & Piezoelectric (Bosch) \\
\hline Control system & Bosch EDC16CP34 \\
\hline $\begin{array}{l}\text { Exhaust gas cleaning } \\
\text { standard }\end{array}$ & $\begin{array}{l}\text { Euro 4 ( with diesel particulate } \\
\text { filter) }\end{array}$ \\
\hline
\end{tabular}

of turbocharging systems forced the development of their regulation systems. The existing solutions for regulating the engine charge air pressure based on pneumatically controlled mechanical actuators give way to electromechanical positioners, mainly in turbochargers with variable angle of turbine steering wheel blades (VNT, VTG) in compression ignition engines. The use of an electromechanical positioner in the turbocharger control enables to achieve any characteristics and ensures fast and accurate regulation of the charge air pressure owing to the position sensor built-in the positioner $[10,13]$.
Electromechanical positioners are exposed to a number of adverse operating factors: mainly vibrations and high temperatures. The first electromechanical positioners were used in the early 2000s in BMW 7 E65 740d engines. In the following years, there was a dynamic development of their construction.

The main faults of these positioners include the damage of the DC motor, including the commutator and carbon brushes (Fig. 3) [7]. The damaged DC motor of the positionercontributes to an excessive load and causes seizures of the VTG turbocharger mechanism. As a result of this phenomenon, the current consumed by the positioner as well as its permissible temperature and vibrations increase. A further consequence of this phenomenon is the damage to the positioner electronics and its connections to the circuit board. The internal electrical connection, as well as the electronic elements of the positioner, are most often exposed to the damage caused by atypical working conditions, as shown in Figure 4 [7].

The gear of the positioner is compressed with the mechanism of controlling the inclination angle of the turbine steering wheel blades (VTG) by means of a band. This causes the damage to the VTG mechanism and affects the operating parameters as well as the durability of the electromechanical positioner. The connection for the Borg Warner turbocharger being the subject of the study is shown in Figure 5 [14].

It can be clearly stated that the durability of the turbocharger and its positioner is influenced by the use of the appropriate service and the compliance with its recommendations. Another equally important factor is the proper load on the engine while driving. 

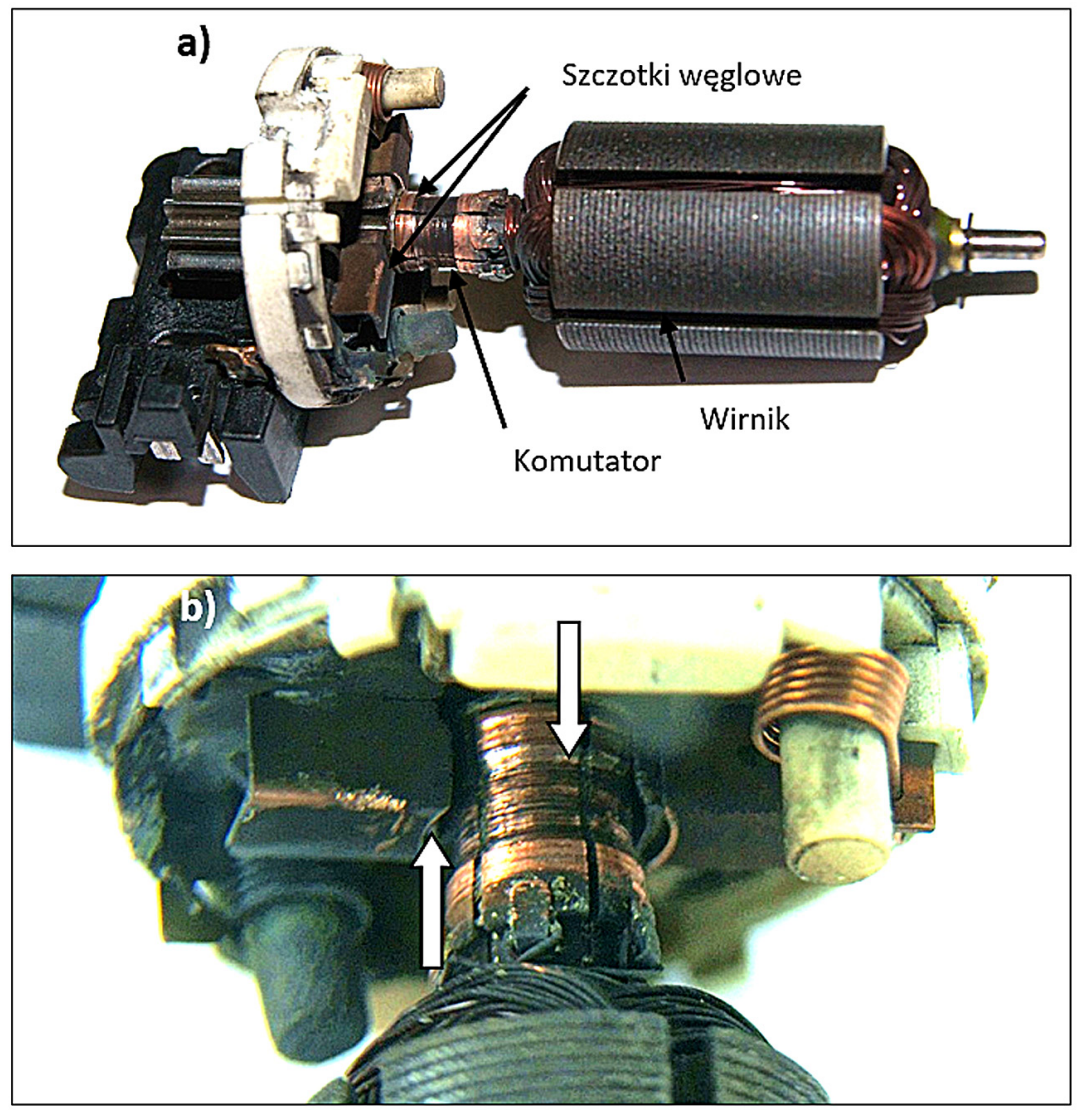

Fig. 3. The damaged commutator and worn out carbon brushes of the DC motor used in the turbocharger positioner; a) protruding commutator from carbon brushes, b) visible significant wear of carbon brushes [7]

a)

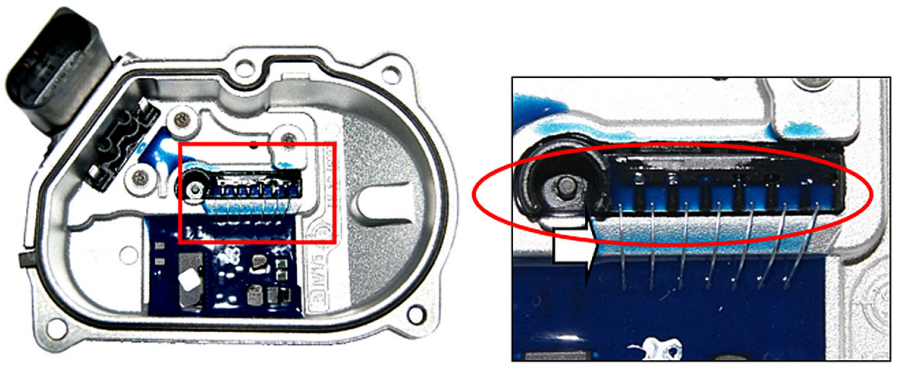

b)

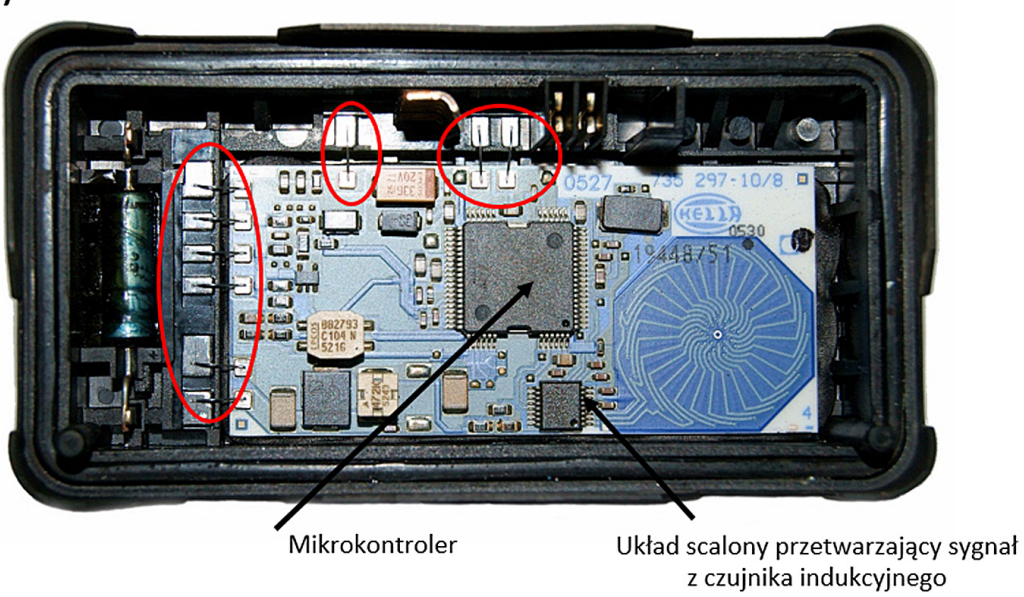

Fig. 4. Areas of internal electrical connections and electronic components of the positioner most often exposed to damage; a) turbocharger positioner used in testing (VDO Siemens), b) Hella turbocharger positioner [7] 


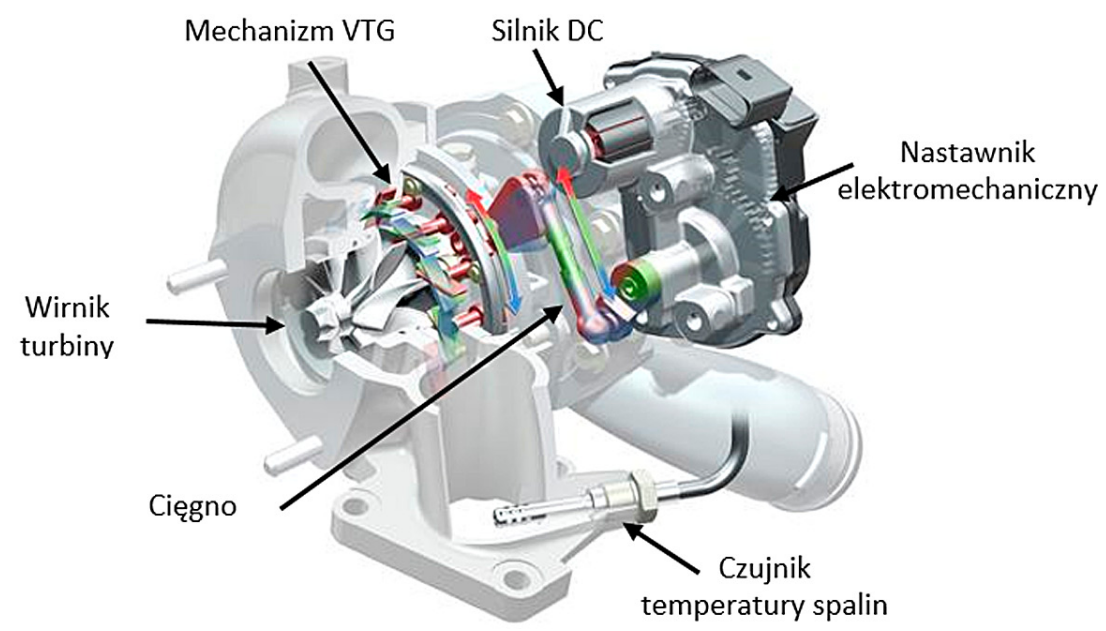

Fig. 5. Mechanical connection (coupling) of the positioner gear with the VTG mechanism of the turbocharger used in the Audi 3.0 V6 TDI engine [14]

\section{Contemporary systems for diagnosing turbocharger positioners}

The compression ignition engines equipped with a turbocharger controlled by an electromechanical positioner during the operation period require the assessment of a number of diagnostic parameters. In this situation, it has to be decided whether or not the electromechanical positioner or the turbocharger has been damaged.

When the engine power stored in the motor controller memory decreases, the error code (DTC) will appear. Such cases were found when the recorded error codes suggested the damages to the turbocharger positioner and in fact the turbocharger itself was damaged. Thus, reading the error code memory only narrows down the search for a broken engine component. Diagnostic computers do not provide full diagnostics of the turbocharger positions either, therefore diagnostic testers are used. In order to analyze the capabilities of testers, available on the market, for diagnostics of turbocharger positioners, they were evaluated in terms of their ability to measure the diagnostic parameters. Six mobile turbocharger positioner testers accessible on the market were selected, four of which were of Polish production (VNNT-1, VNTT-PRO, ATD-1, ActuTest 4000), one tester of Portuguese production (V2) and one of Italian (Gate Test 3). The measurement capabilities of these testers, together with the author's own designed tester, are presented in Table 2.

Only the Turbocline V2 tester from Soure in Portugal enables the measurement of the load on the turbocharger positioner, the position of the pneumatic positioner band and the charge air pressure. The air pressure is measured via the DLC diagnostic connector, only for the vehicles equipped with CAN serial transmission. As the only analysed tester, it allows diagnostics of the turbocharger positioner, which means starting the positioner with a simultaneous measurement of its load. The measurement results are given in two technical conditions: functional or defective.

The assessed manufactured testers do not allow comparing the turbocharger positioner tested diagnostic parameters (Imax) to their limit values. Consequently, only a diagnostician with extensive professional experience is able to determine the actual technical condition of the turbocharger pressure control system. This significantly extends the time of the engine diagnostics.

\section{Diagnostic tester design}

As part of the tests concerning the electromechanical turbocharger positioner of the Audi 3.0 V6 TDI engine using the Bosch KTS 550 diagnostic interface Figure 6 [12], it was not possible to measure the current consumption of the turbocharger positioner, because it was powered independently of the engine control unit power supply. On the basis of the author's own experience, a new diagnostic tester has been developed, which is able to measure the diagnostic levels of the electromechanical turbocharger positioner and additionally it allow implementing the developed diagnostic concept. 
Table 2. Comparison of diagnostic possibilities of analysed positioner testers

\begin{tabular}{|c|c|c|c|c|c|c|c|}
\hline \multirow[b]{2}{*}{ Type of accessible function } & \multicolumn{7}{|c|}{ Analyzed testers } \\
\hline & $\begin{array}{l}\text { Testers } \\
\text { VNNT-1 }\end{array}$ & $\begin{array}{l}\text { Testers } \\
\text { VNNT- } \\
\text { PRO }\end{array}$ & $\begin{array}{l}\text { Tester } \\
\text { ATD-1 }\end{array}$ & $\begin{array}{l}\text { Tester } \\
\text { V2 }\end{array}$ & $\begin{array}{l}\text { Tester } \\
\text { Gate } \\
\text { Test } 3\end{array}$ & $\begin{array}{l}\text { Tester } \\
\text { ActuTest } \\
4000\end{array}$ & $\begin{array}{l}\text { Tester } \\
\text { own }\end{array}$ \\
\hline VTG mechanism setting & $\checkmark$ & $\checkmark$ & $\checkmark$ & $\checkmark$ & $\checkmark$ & $\checkmark$ & $\checkmark$ \\
\hline Measurement of current consumption & & $\checkmark$ & $\checkmark$ & $\checkmark$ & $\checkmark$ & $\checkmark$ & $\checkmark$ \\
\hline Position measurement & & 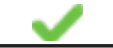 & $\checkmark$ & 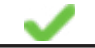 & $\checkmark$ & $\checkmark$ & $\checkmark$ \\
\hline Feedback signal measurement & & $\checkmark$ & $\checkmark$ & $\checkmark$ & $\checkmark$ & $\checkmark$ & $\checkmark$ \\
\hline \multirow{3}{*}{$\begin{array}{l}\text { Positioner movement smoothness test: } \\
\text { - adjustable test speed } \\
\text { - constant test speed }\end{array}$} & $\checkmark$ & $\checkmark$ & $\checkmark$ & $\checkmark$ & $\checkmark$ & $\checkmark$ & $\checkmark$ \\
\hline & & & & $\checkmark$ & & & \\
\hline & $\checkmark$ & $\checkmark$ & $\checkmark$ & & $\checkmark$ & $\checkmark$ & $\checkmark$ \\
\hline \multicolumn{8}{|l|}{ Positioner internal temperature measurement } \\
\hline \multirow{3}{*}{$\begin{array}{l}\text { Motor test (DC):): } \\
\text { - automatic test } \\
\text { - manual test }\end{array}$} & & $\checkmark$ & & & & & $\checkmark$ \\
\hline & & $\checkmark$ & & & & & $\checkmark$ \\
\hline & & & & & & & $\checkmark$ \\
\hline \multicolumn{8}{|l|}{ Turbocharger boost air pressure measurement } \\
\hline Positioner diagnostics & & & & $\checkmark$ & & & 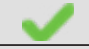 \\
\hline Estimatation in [\%] of the wear level of the positioner & & & & & & & $\checkmark$ \\
\hline $\begin{array}{l}\text { Estimation in [\%] of the positioner movement } \\
\text { resistance }\end{array}$ & & & & & & & 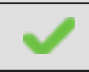 \\
\hline
\end{tabular}

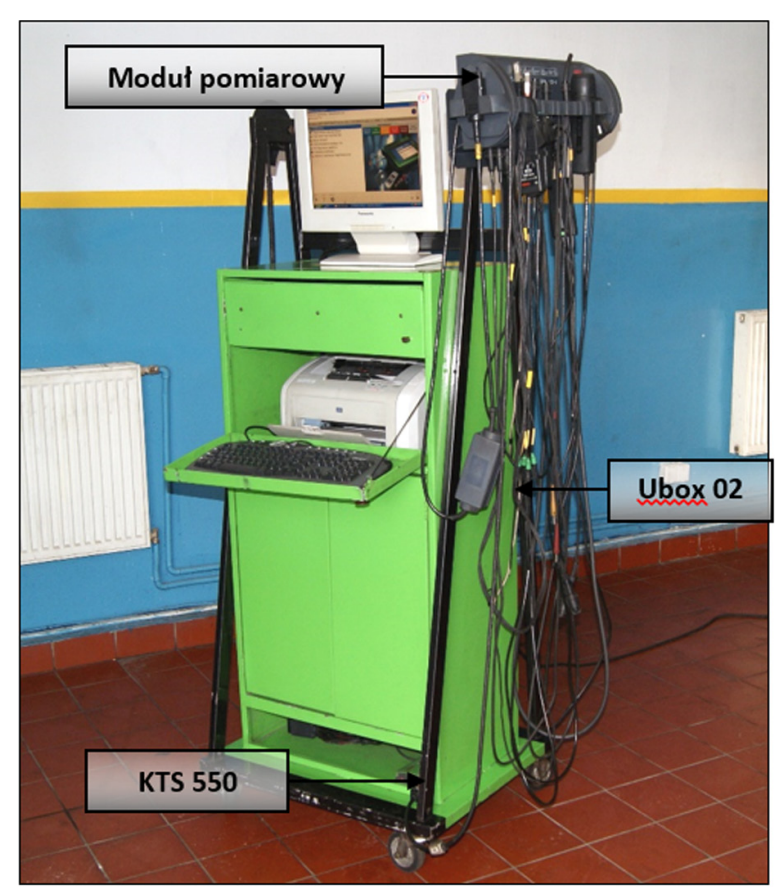

Fig. 6. Bosch FSA 740 diagnostic kit [12]

This tester is characterized by a simplicity of construction and operation. It consists of an $\mathrm{AC}$ adapter and an electronic system for the measurement connectors as well as the user's interface (control panel and LCD display). The main tester element is the Atmel 8-bit microcontroller-AVR. The developed electromechanical turbocharger tester is shown in Figure 7 [7].

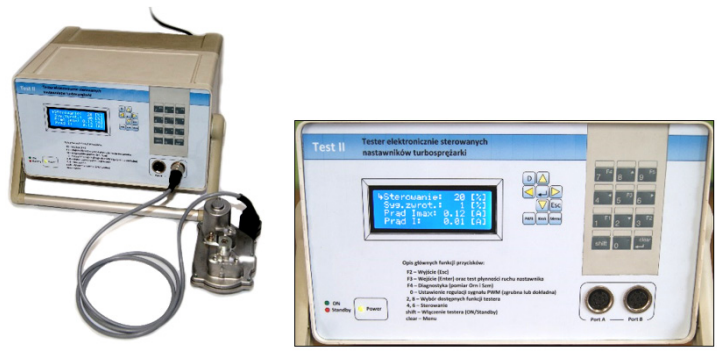

Fig. 7. The author's design turbocharger positioner tester; a) general view of the tester with the electromechanical turbocharger positioner attached;

b) tester control panel [7]

\section{Methodology of the electromechanical turbocharger positioner tests}

The author's own tests of the diagnostic parameters of the electromechanical turbocharger positioner concerning the vehicle mileage were carried out at the Bosch Serwis Logis Car Service in Radom. As mentioned earlier, the research object was an Audi A6 C6 car with a 3.0 V6 TDI compressed ignition engine, as well as a turbocharger with adjustable turbine inclination angle of its steering wheel blades (VTG) with an electromechanical positioner. The methodology of the positioner tests concerned the following measurements of diagnostic parameters:

- Regulator current consumption. This parameter was used due to the fact that the main 
element of the positioner is a DC electric motor. An important feature is that there is a relationship between current consumption and mechanical load. The maximum value (Imax) was used to analyze the results of current consumption measurement of the turbocharger positioner in subsequent measurement cycles;

- The feedback signal from the positioner expressed in percentages. The tested positioner is controlled by a pulse - the width modulation signal (PWM). The engine controller supervises the positioner operation by means of interpreting the feedback signal generated by the turbocharger positioner. The feedback signal of the turbocharger positioner was used due to its diagnostic properties. It allowed evaluating the correctness of the positioner operation and estimation of the position controlled by the positioner of the turbocharger of VTG mechanism.

During the tests of the positioner current consumption, using the tester for the vehicle mileage, a selected group of twenty-four engine diagnostic parameters was also registered due to the economic aspects of its operation and the emission of limited fuel components. This group includes:

- temperatures of coolant, exhaust gases and air sucked into the engine,

- pressure of fuel and charge air,

- the mass of air sucked into the engine,

- angular positions of camshaft, crankshaft and its rotational speed.

In the diagnostic tests of the Borg Warner turbocharger positioner, its current consumption $\mathrm{I}_{\max }$. was determined. In each measurement cycle for a given vehicle mileage, measurements were taken for a loaded positioner combined with a band, turbine steering wheel blades, and for an unloaded one with a disconnected band. On the basis of the measurement of the loaded turbocharger positioner, its movement resistance generated by the turbine steering wheel blades was determined in percentages. The results of measurements of the unloaded turbocharger positioner provided the information owing to which the degree of its consumption was determined.

The obtained test results were the basis for the preparation of two characteristics of the author's own electromechanical turbocharger positioner concerning the Audi A6C6/vehicle mileage:

$$
\begin{aligned}
& \mathrm{I}_{\max 1}=\mathrm{f}(\mathrm{p}) \\
& I_{\max 2}=f(p)
\end{aligned}
$$

where: $I_{\max 1}-$ current consumption of the loaded positioner, $\mathrm{A}$, $\mathrm{I}_{\max 2}-$ current consumption of the unloaded positioner, $\mathrm{A}$, $p$ - vehicle mileage, $\mathrm{km}$.

On the basis of the analysis of these parameters, the percentage of wear of the turbocharger positioner was determined and its movement resistance caused by turbine steering blades was estimated. Figure 8 shows the course of these relationships according to the formula 6.1 for the loaded $\mathrm{I}_{\max 1}$ and unloaded $\mathrm{I}_{\max 2}$ of VTG turbocharger mechanism with a variable angle of inclination of the turbine blades [7].

This graph illustrates the changes in the power consumption of the electromechanical turbocharger positioner until the error code associated with the air-charging system is registered. The graph shows that the current consumption of the unloaded positioner increases along with the vehicle mileage, which is due to the fact that the DC electric motor and the gear work in more and more difficult conditions, because the interior of the positioner housing is filled with the remains of the abrasive wear of the mechanical gear and carbon brushes of the DC motor. Moreover, it should be noted that in the range of 200-250 thousand $\mathrm{km}$ of the vehicle mileage, the current $\mathrm{I}_{2}$ decreases, which might explain the displacement of the mentioned impurities inside the positioner due to the motor vibrations. The manner of distribution of operational impurities inside the positioner and their volume, therefore, affects the power consumption and, in turn, the increase in the current consumption by the load regulator $\mathrm{I}_{\max 1}$ is affected by:

- internal resistance of the positioner movement,

- resistance on the connection of the positioner with the turbocharger band,

- resistance of the steering blade movement.

The following were used to determine the percentage wear of the electromechanical turbocharger positioner and the percentage assessment of its motion resistance caused by the pollution of the turbine steering blades:

- designated range of the correct turbocharger operation, a positioner with a load in the function $I_{\max 1}=f(p)$,

- range of correct operation of an unloaded positioner $I_{\max 2}=f(p)$,

- interpretation of the feedback signal $\mathrm{k}_{\mathrm{sz}}$ positioner with a load and unloaded positioner $\mathrm{k}_{\mathrm{sz2}}$, 


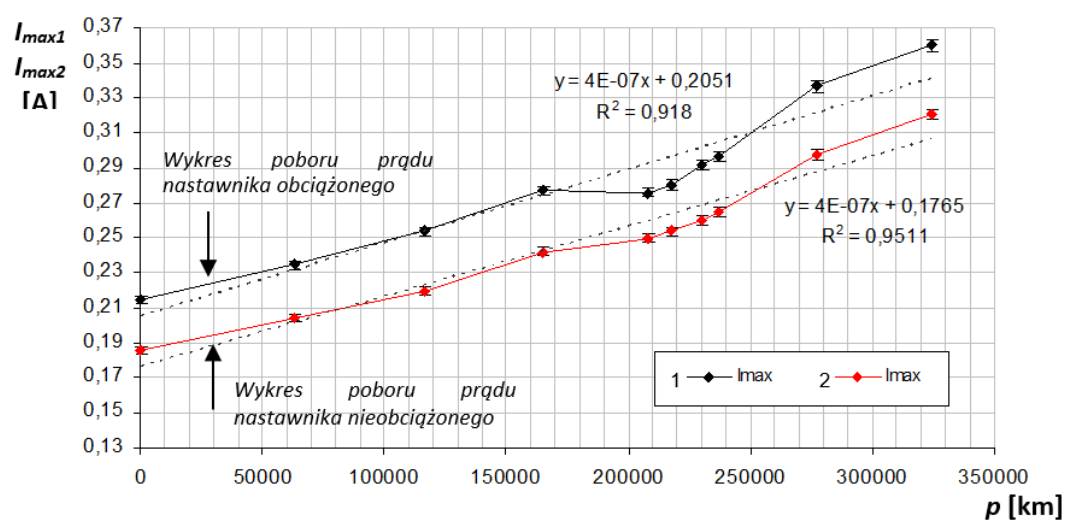

Fig. 8. Summary chart of the current consumption of the loaded $\left(I_{\max 1)}\right.$ and unloaded $\left(I_{\max 2}\right)$ positioner of the turbocharger VTG depending on the vehicle mileage (p) [7]

- the author's own research determining the maximum current consumption of the positioner $\mathrm{a}_{2}$, $\mathrm{b}_{2}$ at continuous load; the exceeding of the load generates an error code indicating a fault

- determining the minimum current consumption for a turbocharger positioner with a $\operatorname{load}\left(\mathrm{a}_{1}\right)$ and unloaded one $\left(\mathrm{b}_{1}\right)$.

The following current consumption ranges were determined for a loaded positioner: $\mathrm{a} 1=0.21 \mathrm{~A}$ and $\mathrm{a} 2=2.33 \mathrm{~A}$, and for an unloaded one: $\mathrm{b} 1=0.18 \mathrm{~A}$ and $\mathrm{b} 2=2.33 \mathrm{~A}$. The ranges of these currents concern only the analyzed Siemens positioner working with a Borg Warner turbocharger on an Audi 3.0 V6 TDI engine. The percentage estimation of the $O_{r n}$ positioner movement resistance caused by the contaminations of the VTG mechanism referred to the designated current consumption range $a_{1}, a_{2}$ of the turbocharger positioner which was determined from the formula [7]:

$$
O_{r n}=\frac{\mathrm{I}_{\mathrm{max} 1}-\mathrm{a}_{1}}{\mathrm{a}_{2}-a_{1}} \times 100 \%
$$

where: $a_{1}$ - lower value of the current consumption of the positioner with a load, $\%$, $\mathrm{a}_{2}$ - upper value of current consumption of the unloaded positioner, $\%$, $I_{\max 1}$ - the current consumption of the positioner with a load, $\%$.

The wear of the $\mathrm{S}_{\mathrm{zn}}$ turbocharger positioner in percentage related to the determined range of the turbocgarger positioner current consumption $b_{1}$ and $b_{2}$ was determined from the formula [7]:

$$
S_{z n}=\frac{\mathrm{I}_{\max 2}-\mathrm{b}_{1}}{b_{2}-b_{1}} \times 100 \%
$$

where: $b_{1}$ - lower,

$b_{2}$ - upper value of the current consumption range of the unloaded positioner [A], $I_{\max 1}$ - current consumption of the loaded positioner in $[\mathrm{A}]$.

\section{Test results}

Figures 9-11 show the results of the measurements of the author's own diagnostic parameters of the electromechanical turbocharger positioner with a variable angle of inclination of VTG turbine blades [7].

They contain the percentage estimation of the wear level of the $S_{z n}$ positioner and the resistance of the $\mathrm{O}_{\mathrm{rn}}$, positioner movement, which are the result of the pollution of blades with abrasive products and deposits from the combustion process inside the engine. Figure 9a contains the diagnostic parameters of the unloaded positioner, which provide the minimum current $\mathrm{I}_{\max }=0.18 \mathrm{~A}$ and the wear of the positioner $\mathrm{S}_{\mathrm{zn}}=0.2 \%$. Fig. $9 \mathrm{~b}$ ) shows: $\mathrm{I}_{\max }=0.21 \mathrm{~A}$ and resistance of the positioner movement $\mathrm{O}_{\mathrm{rn}}$ $=0 \%$ for a loaded positioner. There were $80 \%$ of feedback signals in both cases and they were included in the assumed range of $20-80 \%$. The turbocharger and the positioner were new and fully operational. In Figure 10a and 10b, the tester displayed similar parameters for the unloaded positioner a) and the loaded one b) at a vehicle mileage of about $280,000 \mathrm{~km}$. The turbocharger operation was correct. The degree of the positioner wear was $5 \%$, and the resistance of the positioner movement was $6 \%$. The feedback signal in both cases was $80 \%$, which was acceptable. The Figures $11 \mathrm{a}$ and $11 \mathrm{~b}$ contain 
a)

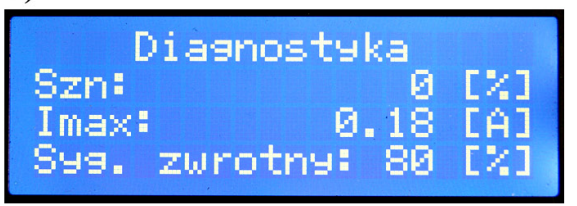

b)

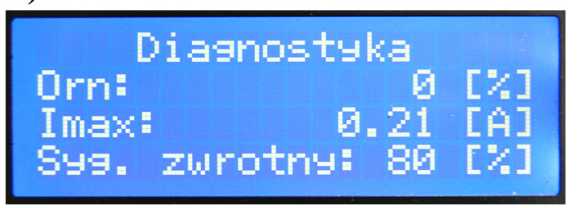

Fig. 9. Diagnostics of the unloaded (a) and loaded (b) positioner carried out with a new turbocharger (minimum current measurements) [7]

a)

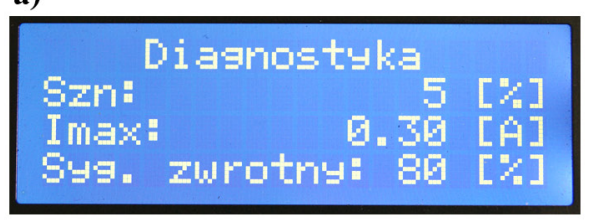

b)

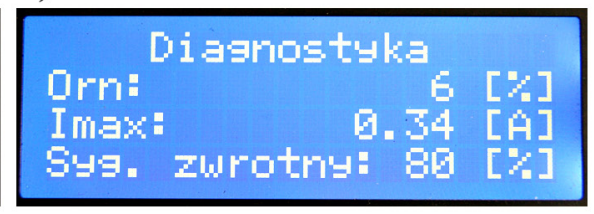

Fig. 10. Diagnostics of the unloaded (a) and loaded (b) turbocharger positioner carried out at a vehicle mileage of approx. 280,000 km (correct operation of the positioner) [7]

a)

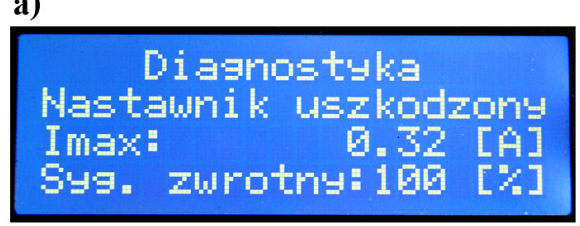

b)

\begin{tabular}{|c|}
\hline 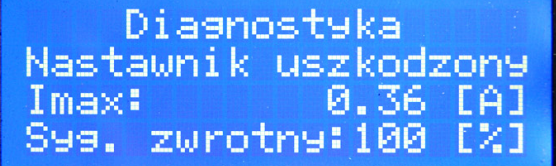 \\
\hline
\end{tabular}

Fig. 11. Diagnostics of the unloaded (a) and loaded (b) turbocharger positioner performed at a vehicle mileage of approx. 324.5 thousand $\mathrm{km}$ (defective positioner) [7]

measurements taken at a vehicle mileage of about $3245000 \mathrm{~km}$. At this vehicle mileage, the tester detected the positioner malfunction, which confirms the value of the feedback signal equal to $100 \%$. It has been saved in the diagnostic memory of the combustion engine controller.

\section{CONCLUSIONS}

On the basis of the author's research conducted in the process of operations of the positioners, some processes were noticed and they were used in the construction of the new tester.

These include:

1. Impurities as abrasive products in the turbine steering wheel blade position control system adequate to the vehicle mileage; they can increase the movement resistance and cause an increase in $I_{\max }$ current consumption by the electric motor of the the positioner contol system. It can be used as a new diagnostic parameter.
2. Stating the fact that it is possible to determine the area of acceptable factor signal values under the arranged test conditions by replacing a given factor with a resistive element and gradually changing its resistance. The engine management system has self-diagnostics, which allows the registration of error codes when the sensor signal exceeds the allowable value. This can be used to recognize the area level of the allowable sensor signal values in case it is not provided by the engine manufacturer.

It should be pointed out that further research in this area should be continued in order to search for further diagnostic parameters, with the extension of the vehicle mileage during its lifetime, especially in relation to trucks. Their mileage often exeeds one million kilometres. The diagnostic capabilities of the tester should be expanded to include further procedures and functions that would also allow the diagnostics of a pneumatic valvecontrolled turbocharger with a turbine blades position sensor. 


\section{REFERENCES}

1. Abd-Alla G.H., Soliman H.A., Badr O.A., AbdRabbo M.F. Effects of diluent admissions and intake air temperature in exhaust gas recirculation on the emissions of an indirect injection dual fuel engine. Energy Conversion and Management, 42(8), 2001.

2. Abdelghaffar A.W., Osman M.M., Saeed M.N. Effects of Coolant Temperature on the Performance and Emissions of a Diesel Engine. ASME Conference Proceedings 14-17.04.2002.

3. Agarwal D., Kumar S.S., Kumar A.A. Effect of Exhaust Gas Recirculation (EGR) on performance, emissions, deposits and durability of a constant speed compression ignition engine. Applied Energy, 88, 2011.

4. Albarbar A., Gu F., Ball A.D. Diesel engine fuel injection monitoring using acoustic measurements and independent component analysis. Measurement, 43, 2010.

5. Danilecki K. Trends in the development of turbocharging systems in automotive vehicles. Combustion Engines, 2(133), 2008.

6. Korte V., Hancock D., Blaxill H. The Mahle downsized engine as technology demonstrator concept, layout and design. MTZ worldwide. 69(1), 2008.

7. Lechowski M. Analysis of diagnostic parameters of the compression ignition engine control system in relation to the vehicle mileage. University of Technology and Humanities, Unpublished Dissertation, Radom, 2014.

8. Lotko M., Lechowski M. Failure frequency of various areas of a vehicle engine as an indicator of their quality. Proceedings of 17th International Conference "TransComp", Zakopane, December 2-5, 2013

9. Lotko W. Development of diesel engine power supply systems. Ed. II, published by Politechnika Radomska, Radom, 2008.

10. Luft S. Fundamentals of engine construction. WKiŁ Warszawa, 2003.

11. Nivesrangsan P., Steel J.A., Reuben R.L. Source location of acoustic emission in diesel engines. Mechanical Systems and Signal Processing, 21, 2007.

12. Robert Bosch GmbH: Information platform ESI [Tronic] 2.0. Ver. 2014/3.

13. Tanin K.V., Wickman D.D., Montgomery D.T., Das S., Reitz R.D. The influence of boost pressure on emissions and fuel consumption of a heavy-duty single-cylinder D.I. diesel engine. SAE Technical Paper Series 1999-01-0840. International Congress and Exposition Detroit, Michigan, March $1-4,1999$.

14. Self Study Book 325 AUDI A6 05 Assemblies Part. Audi AG. Ingolstadt, 01, 2004. 